\title{
Introduction: toward a historical/anthropological approach in neuropsychology
}

\author{
A. Ardila \\ Instituto Colombiano de Neuropsicología, Bogotá, Colombia
}

\begin{abstract}
Anthropology has striven to adequately understand what human living conditions were like 10000,20000 or 100000 years ago. Stone Age (usually divided into the Old Stone or Paleolithic Age, and New Stone or Neolithic Age) extended until some 6000-7000 years ago (Hours, 1982). Agriculture appeared some 10000 years ago; the first cities some 6000 years ago; the first civilizations about 5000 years ago; writing has only five or six thousand years' history; and arithmetical abilities, about 6000 years (Childe, 1936; Sampson, 1985). However, contemporary man (Homo sapiens sapiens) has lived on earth for at least 50000 years (and perhaps, according to current evidence, for 100000 years). We can state with a certain level of security that during this time his brain structural changes have been minimal (Harris, 1983; Kochetkova, 1973). Human brain adaptation was accomplished to survive more appropriately in Stone Age living conditions (existing for about $90 \%$ of this time span on earth) than in those conditions existing today. Only by starting with an analysis of these original conditions, can we understand the specific characteristics and idiosyncracies of human brain adaptation. It would seem reasonable for any neuroscientist to raise the question: to process what type of information did the human brain become adapted for? And consequently, which are the basic cognitive abilities of humans?
\end{abstract}

The search for universal characteristics has guided an important proportion of the anthropological and linguistic activity during the last decades. Anthropology and linguistics have utilized three different approaches, attempting to reconstruct the way of life and the languages spoken by prehistoric man.

(1) Archeological findings are used as elements to reconstruct prehistoric ways of life.

(2) Comparing existing human groups, it is possible to find some common social, behavioral, and linguistic characteristics. These common characteristics most likely already existed in prehistoric times, and are probably the result of specific human biological adaptation. Several thousands of different cultures have been described (Bernatzik, 1957), and contemporary man speaks over 3500 different languages (Swadesh, 1967). Comparing all these cultures and all these languages, some universal characteristics can be discovered (Greenberg, 1978; Wilson, 1975).

(3) Taking existing cultures and/or living languages, similar in specific parameters to prehistoric cultures and/or languages, it is possible to propose how prehistoric living forms and language characteristics could have been with regard to that particular parameter. The validity of this last approach is highly questionable, but it is still used due to the lack of alternative methods.

Anthropology and linguistics have attempted to find basic and universal ways of social organization in different human groups (Van den Berghe, 1979) and fundamental language characteristics (Greenberg, 1978; Hagége 1982). Attempts are made to understand the social organization of prehistoric man and languages existing before living languages. An excellent example of this last point is the reconstruction obtained for the Indo-European language (Anderson, 1973; Lehmann, 1974; Martinet, 1975) whose last speaker passed away several thousand of years ago; and efforts are currently being made to reconstruct even older proto-languages (Shevoroshkin, 1990).

All three approaches (to use archeological findings, to find common characteristics when comparing different human groups, and to use an existing human group, similar in a certain parameter to the prehistoric groups) are potentially useful, and, in fact, have been used in neuropsychological research, although in a restricted way:

(1) We can attempt to reconstruct how some neuropsychological characteristics may have been several thousand years ago, with the help of archeological findings. For instance, we may study handedness in Neolithic humans (Spennemann, 1984).

(2) We may search for commonality among existing groups. For example, we may study aphasic language disturbances throughout different world languages, looking for common characteristics and consequently basic brain language organization (Bates et al., 1987a, b, 1988; Menn and Obler, 1990).

(3) We may study neuropsychological variables in living human groups, similar in a specific parameter to 
prehistoric humans. For instance, we may analyze illiteracy in order to attempt to figure out how linguistic or praxic abilities were in pre-writing societies (e.g. Ardila $e t$ al., 1989b; Lecours et al., 1987, 1988; Rosselli et al., 1990); or we may analyze constructional abilities among Stone Age-like Amazonian Indians (Pontius, 1989).

Undoubtedly, neuropsychology has advanced tremendously in some specific areas; for instance, in the assessment of the sequelae of brain pathology, or in the establishment of clinical/anatomical correlations. However, our fundamental and basic knowledge about the brain organization of cognitive activity under normal and pathological conditions is still limited. Theorization is evidently poor. We do not yet understand sufficently well what can be understood and what can be considered as "basic cognitive ability". Thus, for instance, classification of spatial cognition disturbances is still very confusing and partially contradictory (see "Historical evolution of spatial abilities", pp. 83-87, this volume). Strong mathematical procedures have not yet been applied to the analysis of cognitive activity in neuropsychology, even though psychology in this regard has done better (e.g. Cattell, 1971; Guilford, 1967, 1968; Guilford and Hoepfner, 1971; Matarazzo, 1972). We have barely dealt with individual differences in neuropsychological performance (e.g. Hartlage and Telzrow, 1985), and our understanding of cultural differences is also very limited (Helm, 1992; Ardila, 1993). Matthews (1992), in his International Neuropsychological Society presidential address, stated that ". . . a very limited kind of neuropsychology, appropriate to only a fraction of the world's population, is presented to the rest of the world as if there could be no other kind of neuropsychology, and as if the education and cultural assumptions on which ... neuropsychology is based were obviously universals that applied everywhere in the world" (p. 421).

Historical/anthropological analysis may represent a potentially important approach for neuropsychology. This analysis may provide behavioral neurosciences with a better and more accurate understanding of brain organization of cognitive processes under normal and abnormal conditions.

An interest in cultural and historical issues has recently been observed in neuropsychology. This interest in obtaining a better understanding of cultural and historical issues in the neuropsychology sphere is not, however, completely new: some precursor attempts are found in the literature. For instance, A.R. Luria is well known in neuropsychology for his contributions to the analysis of brain organization of language, and for his research on the prefrontal syndrome. However, his cultural approach to neuropsychology is less recognized. Nonetheless, in a certain way, Luria departed from the analysis of cultural issues (Luria, 1934, 1976) and moved further towards neuropsychology. Unfortunately, most of his cross-cultural research proposals in neuropsychology (i.e. the analysis of hemi-neglect syndrome in different cultural groups, the cross-linguistic analysis of aphasias, the comparison of alexias in different writing systems, etc.) never became concrete research programs, but his great interest and emphasis on cultural and historical variables in neuropsychology was always reflected in his writing.

During the last few years a small but significant number of papers devoted directly or indirectly to the analysis of cultural variables in neuropsychological performance have been recorded in the literature, for example: bilingualism research (e.g. Albert and Obler, 1978; Vaid, 1986; Paradis, 1987; Dupont et al., 1992); studies on illiteracy (e.g. Lecours et al., 1987, 1988; Matute, 1988; Ardila et al., 1989b; Rosselli et al., 1990); the crosslinguistic analysis of aphasia (e.g. Bates et al., 1987a, b, 1988; Menn and Obler, 1990); research about the influence of socio-educational factors in neuropsychological performance (e.g. Ostrosky et al., 1985; Rosselli and Ardila, 1990; Ardila et al., 1992); and studies on cultural variables in handedness (e.g. Bryden, 1987; Ardila et al., 1989a; Harris, 1990; Bryden et al., 1993).

The need for a strong cross-cultural neuropsychology study is evident. This collection of papers attempts to direct the attention of behavioral neuroscience toward some potentially relevant historical and cultural variables in neuropsychological performance. The purpose of this monograph issue is, in consequence, multiple:

(1) To integrate some information regarding cross-cultural differences in neuropsychological performance.

(2) To review some evidence about the historical origins of cognitive activity.

(3) To analyze how the inclusion of a historical and cultural perspective in behavioral neurosciences can contribute to a better understanding about the brain organization of cognition.

(4) To present some general guidelines for future research in the area.

Different problems are analyzed.

In the first paper ("Prefrontal abilities") D.F. Benson proposes that the neuroanatomical region that has most prominently altered with the advancing cognitive competency of the human brain is the prefrontal cortex. Despite the fact that the prefrontal cortex does not appear to contain the neural networks that carry out cognitive activities, the management and control of cognitive activities ("metacognition"), so uniquely characteristic of the human, appears dependent upon the prefrontal cortex.

The paper "Historical evolution of spatial abilities" analyzes the development and cross-cultural differences of spatial cognition. It is proposed that: (1) spatial abilities are found to be significantly associated with the complexity of geographical conditions and survival demands; and (2) spatial cognition has evolved in a parallel way with 
cultural evolution and ecological demands. Contemporary city man may be using those spatial abilities in some new, conceptual tasks that did not exist in prehistoric times (mathematics, reading, writing, mechanics, music, etc.).

In the paper "On the origins of calculation abilities" it is pointed out that counting, starting with finger sequencing, is observed in different, both ancient and contemporary, cultures, whereas number representation and arithmetic abilities are found only during the last 5000-6000 years. The paper analyzes the rationale of selecting a base of ten in most numerical systems, and the clinical association between acalculia and finger agnosia. Finger agnosia, rightleft discrimination disturbances, semantic aphasia, and acalculia are proposed to comprise a single neuropsychological syndrome associated with left angular gyrus damage. It is hypothesized that acalculia, finger agnosia and disorders in right-left discrimination (as in general, in the use of spatial concepts) result from the disruption of common cognitive mechanisms.

The question of how other individuals are recognized is also analyzed ("People recognition: a historical anthropological perspective"). It is emphasized that not only visual, but also auditory and even olfactory information may be involved in people recognition. Visual information is proposed to include not only the perception of faces, but also the perception of whole body and gait, clothes, emotional expressions, and individual marks. Departing from clinical observation, a model for people recognition is presented. It is hypothesized that different "subsystems" or "modules" may be involved in individuals' recognition; "living" versus "non-living", "own species" versus "other species", "familiar" versus "non-familiar", "males" versus "females", and "individual identification" versus "emotional identification".

In the final paper "Neuropsychology of illiteracy", M. Rosselli reviews brain organization of cognition, and cognitive sequelae of brain pathology in illiterates. She concludes that: (1) cognitive abilities, as measured by standard neuropsychological tests, are strongly influenced by schooling background; and (2) educational and cultural variables may affect the degree (but not the direction) of hemispheric dominance for language, and other cognitive abilities. A more bilateral representation of cognitive abilities in illiterates is hypothetized.

The authors of this collection of papers sincerely hope this monograph will further interest in the analysis of historical and cultural variables in cognition, and will contribute to the development and strengthening of cross-cultural neuropsychology.

\section{REFERENCES}

Albert ML and Obler LK (1978) The Bilingual Brain. Academic Press, New York.
Anderson JM (1973) Structural Aspects of Language Change. Longman, London.

Ardila A (1993) Directions of research in cross-cultural neuropsychology. XXI Annual Meeting International Neuropsychological Society, Galveston (USA).

Ardila A, Ardila D, Bryden MP, Ostrosky F, Rosselli M and Steenhuis R (1989a) Effects of cultural background and education on handedness. Neuropsychologia, 27, 893-898.

Ardila A, Rosselli M and Rosas P (1989b) Neuropsychological assessment in illiterates: Visuospatial and memory abilities. Brain and Cognition, 11, 147-166.

Ardila A, Rosselli M and Ostrosky F (1992) Socioeducational factors in neuropsychological assessment. In: Handbook of Neuropsychological Assessment: A Biopsychosocial Perspective (Eds AE Puente and RJ McCaffrey), pp. 181-182. Plenum Press, New York.

Bates E, Friederici A and Wulfeck B (1987a) Grammatical morphology in aphasia: Evidence form three languages. Cortex, 23, 545-574.

Bates E, Friederici A and Wulfeck B (1987b) Comprehension in aphasia: A cross-linguistic study. Brain and Language, 32, 19-67.

Bates E, Friederici A, Wulfeck B and Juarez LA (1988) On the preservation of word-order in aphasia: Cross-linguistic evidence. Brain and Language, 33, 232-365.

Bernatzik HA (1957) Razas y Pueblos del Mundo [World Races and People], Vols 1-3. Ediciones Ave, Barcelona.

Bryden MP (1987) Handedness and cerebral organization: Data from clinical and normal populations. In: Duality and Unity of the Brain (Ed D Ottoson), pp. 55-70. MacMillan, Houndmills, UK.

Bryden MP, Ardila A and Ardila O (1993) Handedness in native Amazonians. Neuropsychologia, 31, 301-308.

Cattell RB (1971) Abilities: Their Structure, Growth and Action. Houghton-Mifflin, Boston.

Childe VG (1936) Man Makes Himself. Pitman, London.

Dupont S, Ardila A and Rosselli M (1992) Neuropsychological assessment in bilinguals. In: Handbook of Neuropsychological Assessment: A Biopsychosocial Perspective (Eds AE Puente and RJ McCaffrey), pp. 193-210. Plenum Press, New York.

Greenberg JH (1978) Universals of Human Language, Vols 1-4. Stanford University Press, Stanford, CA.

Guilford JP (1967) The Nature of Human Intelligence. McGrawHill, New York.

Guilford JP (1968) Intelligence has three facets. Science, 160, 615-620.

Guilford JP and Hoepfner R (1971) The Analysis of Intelligence. McGraw-Hill, New York.

Hagége C (1982) La Structure des Langues. Presses Universitaires de France, Paris.

Harris M (1983) Cultural Anthropology. Harper \& Row, New York.

Harris JL (1990) Cultural influences on handedness: Historical and contemporary theory and evidence. In: Left-Handedness: Behavioral Implications and Anomalies (Ed S Coren), pp. 195-258. North-Holland, Amsterdam.

Hartlage LC and Telzrow CF (1985) The Neuropsychology of Individual Differences. Plenum Press, New York.

Helm JE (1992) Why is there no study of cultural equivalence in standardized cognitive ability testing? American Psychologist, 47, 1083-1101.

Hours F (1982) Les civilisations du Paleolithique. Presses Universitaires de la France, Paris. 
Kochetkova VI (1973) Paleoneurology. Moscow State University Press, Moscow (in Russian).

Lecours RL, Mehler J, Parente MA, Caldeira A et al. (1987) Illiteracy and brain damage 1: aphasia testing in culturally contrasted populations (control subjects). Neuropsychologia, 25, 231-245.

Lecours AR, Mehler J, Parente MA et al. (1988) Illiteracy and brain damage III: A contribution to the study of speech and language disorders in illiterates with unilateral brain damage (initial testing). Neuropsychologia, 26, 575-589.

Lehmann WP (1974) Proto-Indian-European Syntax. University of Texas Press, Austin.

Luria AR (1934) The second psychological expedition to Central Asia. Journal of Genetic Psychology, 41, 255-259.

Luria AR (1976) Cognitive Development: its Cultural and Social Foundations. Harvard University Press, Cambridge, MA. (Originally written in 1930; published in Russian in 1974 under the title About the Historical Development of Cognitive Processes.)

Martinet A (1975) Evolution de Langues et Reconstruction. Presses Universitaires de France, Paris.

Matarazzo JD (1972) Wechsler's Measurement and Appraisal of Adult Intelligence. Oxford University Press, New York.

Matthews CG (1992) Truth in labeling: Are we really an international society? Journal of Clinical and Experimental Neuropsychology, 14, 418-426.

Matute E (1988) El aprendizaje de la lectoescritura y la especializacion hemisferica para el lenguaje [Reading and writing learning and the hemispheric specialization for language]. In: Lenguaje Oral y Escrito (Eds A Ardila and F Ostrosky-Solis), pp. 310-338. Editorial Trillas, Mexico.

Menn L and Obler LK (1990) Agrammatic Aphasia: A Cross-
Language Narrative Sourcebook. John Benjamin, Amsterdam.

Ostrosky F, Canseco E, Quintanar L, Navarro E and Ardila A (1985) Sociocultural effects in neuropsychological assessment. International Journal of Neuroscience, 27, 53-66.

Paradis M (1987) The Assessment of Bilingual Aphasia. Lawrence Erlbaum Associates, Hillsdale, NJ.

Pontius AA (1989) Color and spatial error in block design in stone-age Auca Indians: Ecological underuse of occipital-parietal system in men and of frontal lobes in women. Brain and Cognition, 10, 54-75.

Rosselli M and Ardila A (1990) Effects of age, education and gender on the Rey-Osterrieth Complex Figure. The Clinical Neuropsychologist, 5, 370-376.

Rosselli M, Ardila A and Rosas P (1990) Neuropsychological assessment in illiterates II: Language and praxic abilities. Brain and Cognition, 12, 281-296.

Sampson G (1985) Writing Systems. Stanford University Press, Stanford, CA.

Shevoroshkin V (1990) The Mother Tongue: how linguistics have reconstructed the ancestor of all living languages. The Sciences, May/June, 20-27.

Spennemann DR (1984) Handedness data on the European Neolithic. Neuropsychologia, 22, 613-616.

Swadesh M (1967) El Lenguaje y la Vida Humana [Language and Human Life]. Fondo de Cultural Economica, Mexico.

Vaid J (1986) Language Processing in Bilinguals. Lawrence Erlbaum Associates, New York.

Van den Berghe PL (1979) Human Family Systems. Elsevier, New York.

Wilson AO (1975) Sociobiology. The Belknap Press of the Harvard University Press, Cambridge, MA. 


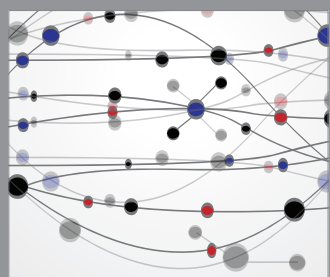

The Scientific World Journal
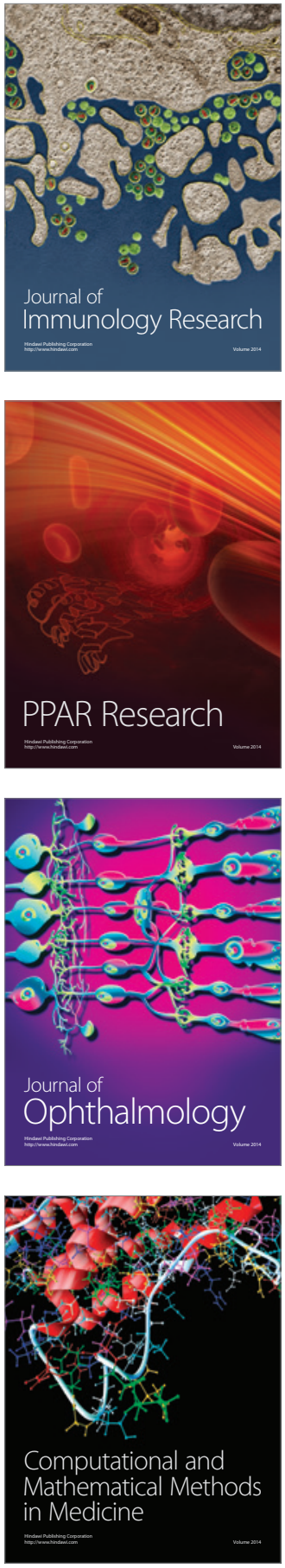

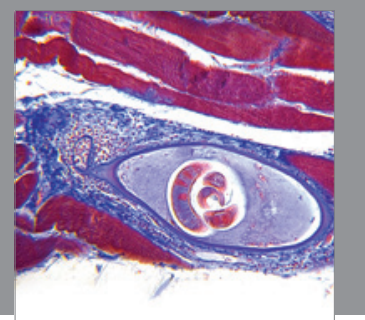

Gastroenterology

Research and Practice
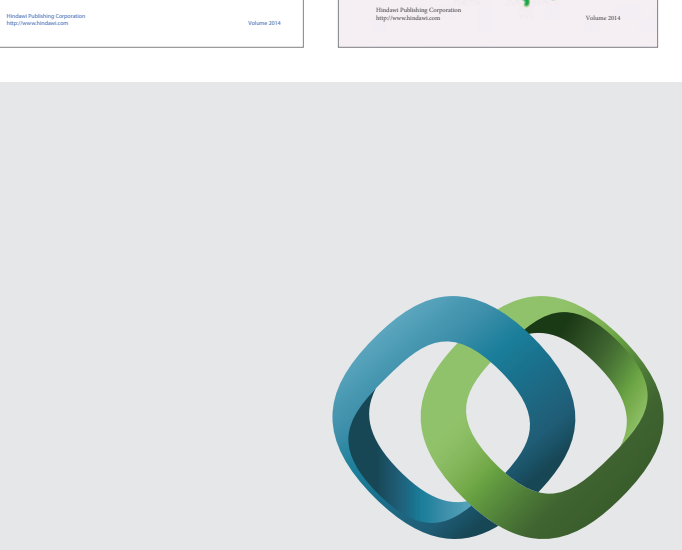

\section{Hindawi}

Submit your manuscripts at

http://www.hindawi.com
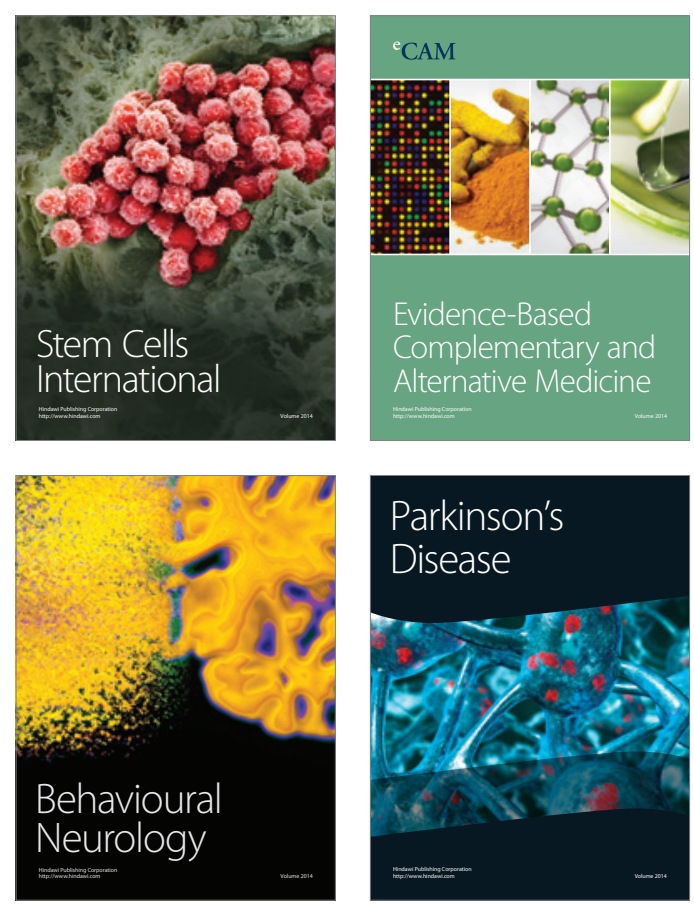

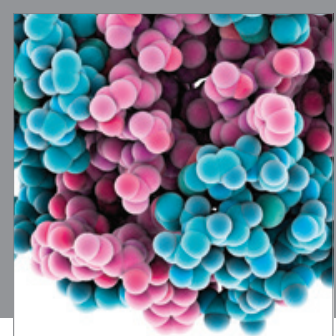

Journal of
Diabetes Research

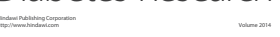

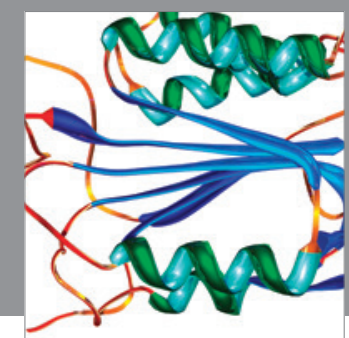

Disease Markers
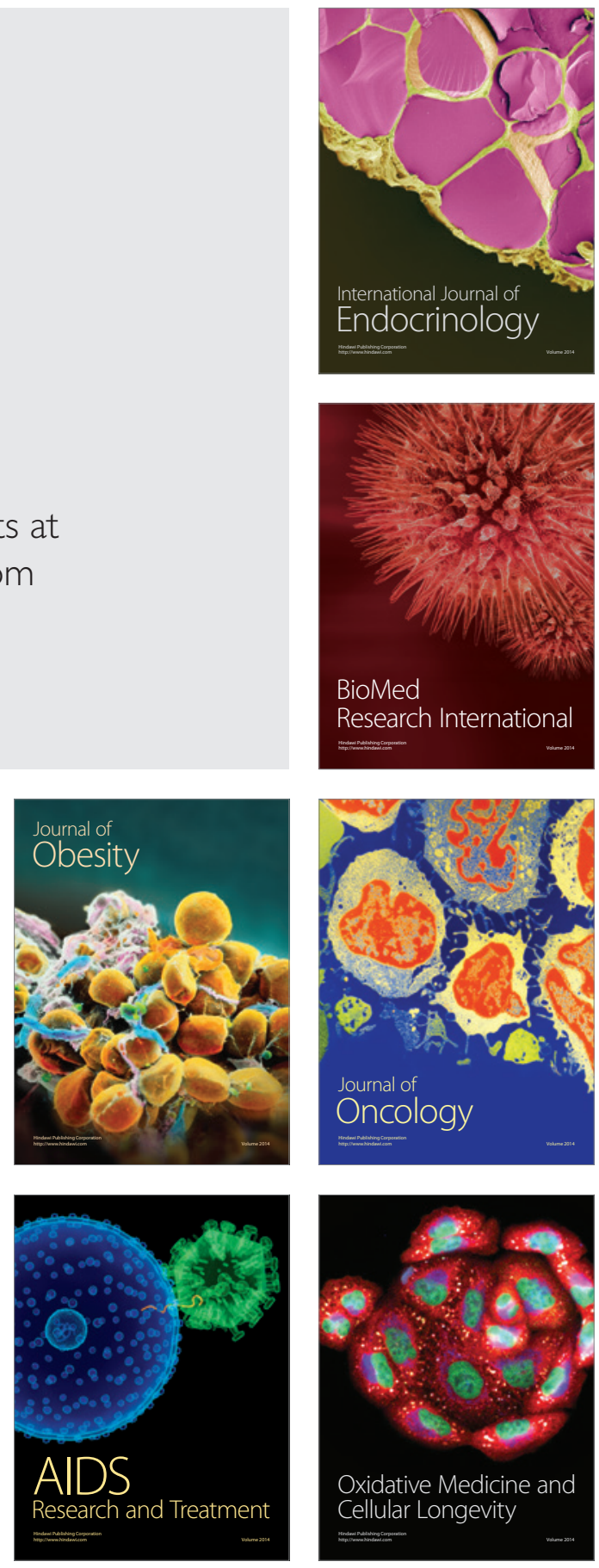